\title{
Critical neuroscience-or critical science? A perspective on the perceived normative significance of neuroscience
}

\author{
Stephan Schleim ${ }^{1,2 *}$ \\ Theory and History of Psychology, Heymans Institute for Psychological Research, Faculty of Behavioral and Social Sciences, University of Groningen, Groningen, \\ Netherlands \\ ${ }^{2}$ Research Center for Neurophilosophy and Ethics of Neurosciences, Munich Center for Neurosciences, Ludwig-Maximilians-University Munich, Munich, Germany
}

Edited by:

Jan Slaby, Freie Universität Berlin,

Germany

\section{Reviewed by:}

Philipp Haueis, Max Planck Institute

for Cognitive and Brain Sciences,

Germany

Clifford Van Ommen, Massey

University, New Zealand

*Correspondence:

Stephan Schleim, Theory and

History of Psychology, Heymans

Institute for Psychological Research,

Faculty of Behavioral and Social

Sciences, University of Groningen,

Grote Kruisstraat 2/1, 9712 TS

Groningen, Netherlands

e-mail: s.schleim@rug.nl
Members of the Critical Neuroscience initiative raised the question whether the perceived normative significance of neuroscience is justified by the discipline's actual possibilities. In this paper I show how brain research was assigned the ultimate political, social, and moral authority by some leading researchers who suggested that neuroscientists should change their research priorities, promising solutions to social challenges in order to increase research funds. Discussing the two examples of cognitive enhancement and the neuroscience of $(\mathrm{im})$ moral behavior I argue that there is indeed a gap between promises and expectations on the one hand and knowledge and applications on the other. However it would be premature to generalize this to the neurosciences at large, whose knowledge-producing, innovative, and economic potentials have just recently been confirmed by political and scientific decision-makers with the financial support for the Human Brain Project and the BRAIN Initiative. Finally, I discuss two explanations for the analyzed communication patterns and argue why Critical Neuroscience is necessary, but not sufficient. A more general Critical Science movement is required to improve the scientific incentive system.

Keywords: neuroethics, cognitive enhancement, moral decision-making, forensic neuroscience, science communication
"Ideologies, philosophies, religious doctrines, world-models, value systems, and the like will stand or fall depending on the kinds of answers that brain research eventually reveals. It all comes together in the brain" (Sperry, 1981: 4).

In the year Roger W. Sperry received the Nobel Prize for his research on the functional specialization of the cerebral hemispheres, he expressed worries that the public had lost trust in science, including his own field: neuroscience. Indeed, an editorial in Science written by the President (on leave) of the New York University and Deputy Secretary of Energy John C. Sawhill warned of the negative consequences of a "public disillusionment", "credibility gap", and "growing cynicism" about science (Sawhill, 1979). In Sperry's view, neuroscientists should change their research priorities and emphasize the possible social benefits of their enterprise; this should be easy, he argued, because all political, social, and philosophical matters were ultimately subjects of brain research. This shift should allow a fusion of science and religion, the descriptive and the prescriptive, to overcome global problems caused by increasing population, pollution, poverty, and energy demands (Sperry, 1981). Twenty-five years later his former $\mathrm{PhD}$ student Michael S. Gazzaniga would revive this vision in the introduction of his book "The Ethical Brain" (Gazzaniga, 2005; see also Schleim, 2005; Schleim and Schirmann, 2011).

In the presidential declaration heralding the "Decade of the Brain" 10 years after Sperry voiced his concerns, the broad social potential of the neurosciences was explained with respect to neurodegenerative diseases as well as the "War on Drugs". President George H. W. Bush called "upon all public officials and the people of the United States to observe that decade with appropriate programs, ceremonies, and activities" (Bush, 1990). The Commission of the European Communities soon followed with a similar declaration heralding the "European decade of brain research" (Pandolfi, 1993). Sperry's fears that the neurosciences might suffer budget cuts were thus overcome in the 1990s. In spite of recent investigations of science communication reporting a raise in "neuroskepticism" in scholarly as well as public reports on neuroimaging (Rachul and Zarzeczny, 2012; Whiteley, 2012) and broader analyses into "neuromythology" (Hasler, 2012; Satel and Lilienfeld, 2013), the political-scientific decisions in 2013 to fund the major research endeavors Human Brain Project and BRAIN Initiative emphasized that the neurosciences still enjoy high public confidence in their knowledge-producing capacities as well as their potential to drive technological innovation and, not the least, economic growth.

Critical Neuroscience is a young initiative to probe "the extent to which discussion of neuroscience ... matches the achievements and potential of neuroscience itself". ${ }^{1}$ By means of critique and including interdisciplinary perspectives, its members try to better understand the knowledge-producing and -communication

\footnotetext{
${ }^{1}$ See the project description on their website (http://www.criticalneuroscience.org/\#1; accessed February 23 2014).
} 
processes in the neurosciences and its wider ramifications (Choudhury et al., 2009; Slaby and Choudhury, 2012). Notably, Jan Slaby asked: "Does neuroscience indeed have such wideranging effects or are we collectively overestimating its impacts at the expense of other important drivers of social and cultural change?" (Slaby, 2010: 397). In this paper, I follow a two-fold strategy to propose a preliminary answer to his question: first, I skeptically ${ }^{2}$ discuss two examples of neuroscience technologies that would obviously have strong social/normative implications when applied, namely (1) pharmacological enhancement and (2) (im)moral neuroscience; second, I relate Critical Neuroscience to (3) recent critical analyses of the general scientific knowledgemaking and -communication processes.

\section{PROMISES OF PHARMACOLOGICAL ENHANCEMENT}

That healthy people use psychoactive substances to influence their experiences or relations with other people and society was not new in the early 2000s: besides references to ancient cultural or religious practices, the medical-anthropological investigation of what Nicolas Rasmussen called "America's First Amphetamine Epidemic 1929-1971" provided clear evidence for this (Rasmussen, 2008a,b). New was framing the phenomenon in terms of "cognitive enhancement". ${ }^{3}$ Indeed, also the President's Council on Bioethics's related report "Beyond Therapy: Biotechnology and the Pursuit of Happiness" published at the beginning of that decade discussed superior performance exclusively with respect to sports and muscle enhancement (Bioethics Council, 2003). When addressing the possibility of stimulant drugs as behavior improvement, they strongly emphasized socialmoral over cognitive alterations, namely, children's "ability and willingness to be considerate, show respect, pay attention, carry out assignments, accept responsibility, deal with stress and disappointment, and practice self-control" (Bioethics Council, 2003: 71). At that time, the drugs that would later be discussed as possible cognitive enhancement substances by neuroethicists had already been known for years (modafinil) to decades (amphetamine, methylphenidate).

The sudden emphasis on cognitive performance by scientific researchers, particularly performance-enhancing behavior of students (Farah et al., 2004; Greely et al., 2008), coincided with political initiatives to define a nation's value in terms of its citizen's "mental capital" (Beddington et al., 2008; Foresight, 2008; see also Slaby, 2010). Obviously, the science underlying the "mental wealth of nations" (Beddington et al., 2008), that is, cognitive neuroscience, became of utmost public importance, because "if we are to prosper and thrive in our changing society and in an increasingly interconnected and competitive world, both our mental and material resources will be vital" (Foresight, 2008: 9). Notably, the central claim that students increasingly consumed

${ }^{2}$ Note that skepticism and doubt are often considered as basic norms or values of science in official declarations of scientific bodies (IAC/IAP, 2012; DFG, 2013).

${ }^{3}$ An ISI Web of Science topic search for "cognitive enhancement" yields 661 hits with the first incidence in 1986; the 1990s, aggregated, have 51 incidences or 4.3 annually; the 2000 s 274 or 22.9 , respectively; the first 4 years of the 2010s already exceed this whole previous decade with 319 incidences or 79.8, respectively. stimulant drugs to become better could not be confirmed so far (Smith and Farah, 2011). It should be considered, though, that many of the prevalence surveys define enhancement as mutually exclusive with treatment, excluding consumption as soon as drugs are medically prescribed. This neglects the possible interpretation that there actually is an increase in stimulant consumption due to a medicalization of normal or slightly sub-threshold cognitive performance (Rubin, 2004; Abraham, 2010). ${ }^{4}$

While stimulant drugs may improve performance of healthy people in some cognitive tests under laboratory conditions (Repantis et al., 2010; Smith and Farah, 2011), their benefit in real-life settings is much less clear. Pharmacologists like Boris B. Quednow provided theoretical arguments for why we should not expect too much given the current knowledge of brain function (Quednow, 2010). For example, just increasing neurotransmitter levels beyond normal levels is likely to decrease performance. Quednow's suggestion to call stimulants "secondary enhancers" because their effects on cognition seem to be (at least partially) mediated by enhancing motivation-how people feel about performance and pressure-is supported by a recent survey of stimulant consumers' self-descriptions at an "elite university" in the USA that identified four emotional patterns: feeling up, drivenness, interestedness, and enjoyment (Vrecko, 2013). Thus, "cognitive enhancement" may not be that cognitive, after all.

Even more sobering are two broader observations: first, that many pharmaceutical companies decided to close their psychiatric laboratories because further efforts do not seem to justify the expected benefits (Amara et al., 2011; van Gerven and Cohen, 2011); second, that even in cases of diagnosed ADHD-thus in the presence of a therapeutic behavioral-cognitive targetthe prescription of stimulants does not seem to make a lasting difference to performance (Currie et al., 2013; Sharpe, 2014). If the prospects of pharmacological research in these therapeutic contexts are poor, after decades of intensive research and in the light of developed clinical models, the speculations on the effects in healthy people seem even more preposterous.

Disturbingly, a recent communication analysis found evidence that the media are biased towards positive representations of pharmacological enhancement and an exaggeration of its prevalence (Partridge et al., 2011). In line with this research, anecdotal evidence suggested that scholarly publications by scientific experts themselves underlie this communication pattern (Schleim, 2010). This raises the suspicion that the debate keeps reinforcing itself while lacking strong evidence that the expectations can be met in the near future. From a communication perspective it can be a successful attention-maximizing strategy to first hype a new discovery/development and later debunk it, thus multiplying the number of reports, a pattern not uncommon with respect to pharmacological discoveries (Williams et al., 2008).

\footnotetext{
${ }^{4}$ The annual production quotas in the USA increased from $12,700 \mathrm{~kg}$ in 2004 , when they were already on a high level, to $49,000 \mathrm{~kg}$ in 2014 for amphetamine and $28,693 \mathrm{~kg}$ to $96,750 \mathrm{~kg}$ for methylphenidate; that is, almost four-fold for the former and 3.4-fold for the latter (US Drug Enforcement Administration, October 2 2013).
} 


\section{PROMISES OF (IM)MORAL NEUROSCIENCE}

Morality in its several facets, what people are doing and why as well as what they should do, has fascinated thinkers at least since antiquity (Nadelhoffer et al., 2010). It is common to distinguish the prescriptive, what should be done, and the descriptive, what is the case. Philosophers developed arguments that it amounts to a fallacy to derive a prescription from a pure description (Moore, 1903). Initially we have seen the two statements by Sperry and Gazzaniga clearly expressing the idea that descriptive knowledge of the brain will inform us on what we should do. Accordingly, Joshua D. Greene and colleagues who confronted students with descriptions of moral dilemmas in a brain scanner suggested from the outset that their research could decide the stalemate position in which, in their view, moral philosophers had been caught for a long time (Greene et al., 2001, 2004). Their attempt was twofold, associating (1) utilitarian/consequentialist judgments favoring the benefit of the greatest number of people with "cognitive/rational" brain areas (e.g., the dorsolateral prefrontal cortex) and evolutionary recent developments; and (2) other kinds of judgments favoring people's intentions or general principles/duties with "emotional/irrational" brain areas (e.g., the ventromedial prefrontal cortex and amygdalae) and evolutionary ancient developments (Greene et al., 2004; Greene, 2008). Indeed, these interpretations were endorsed quickly by moral philosophers arguing that ethical utilitarianism has a rational basis, while a competing deontological ethics has not (Singer, 2005).

It goes without saying that the association with a certain brain area or a particular evolutionary stage does not in itself have any prescriptive force; however, with a rather basic assumption that a moral theory should suffice demands of rationality the argument becomes complete. Virtually all aspects of the experiment and its interpretations have been criticized by neuroscientists, psychologists, and philosophers alike (e.g., Joyce, 2008; Schleim, 2008; Berker, 2009; Kahane, 2011; Waldmann et al., 2012). However, for moral neuroscience to become a scholarly and public communication success (see Figure 1), the prescriptive/normative claims did not have to be justified; it was sufficient that they seemed plausible, that it seemed that science aided by brain scanners has genuinely new ways of informing or perhaps even deciding philosophical/moral debates (Schleim, forthcoming).

Generations of anthropologists and moral psychologists before had gathered evidence on the development, cognitive-emotional mechanisms, and cultural diversity of morality, but suddenly in 2001 with the publication of the first neuroimaging experiments the situation seemed to have changed. It seems fair to say that of the seven different psychological-neuroscientific theoretical accounts of morality distinguished by Jorge Moll et al., all the evidence gathered hitherto does not unequivocally favor any particular one (Moll et al., 2005). While the science communication accompanying the original study by Greene et al. suggested the philosophical relevance of the research, even putting forward the idea that the new findings could make moral philosophers superfluous (Helmuth, 2001), so far the opposite has been the case: theoreticians of all kinds responded to the prescriptive/normative claims and emphasized how these neuroscientific reports rely on theoretical presumptions and individual interpretation.

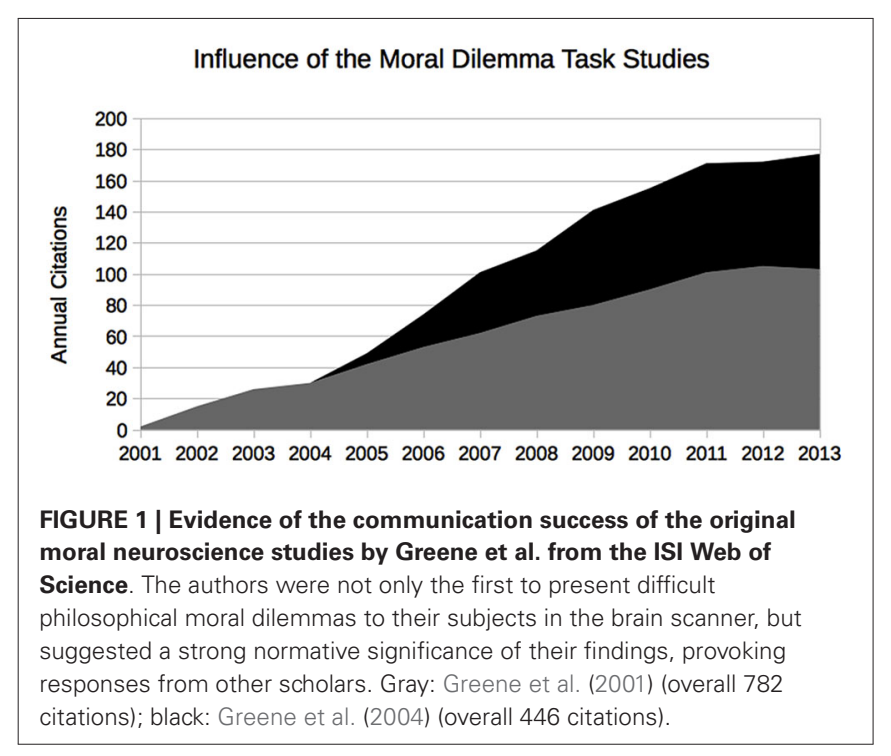

While theoretical in its scope, moral neuroscience is used to provide the ultimate answers of human right and wrong that Sperry and Gazzaniga called for. More applied/technical implications are promised by the complementary research that might be coined "immoral neuroscience": the investigation of what makes us behave immorally or criminally. The historian Peter Becker suggested that criminal behavior was an essential aspect of biological/neuroscientific accounts of human beings to emphasize their social relevance (Becker, 2012). Indeed, journals like Nature feature detailed reports when neuroscientists provide expert testimony in criminal courts (e.g., Hughes, 2010). ${ }^{5}$ Recently, Adrian Raine coined the notion that criminals have "broken brains, brains that are physically different from those of the rest of us" (Raine, 2013: 180). Based on the present findings of (im)moral neuroscience and an optimistic evaluation of future discoveries, he predicts the development of a new biopsychological screening and intervening program incorporating extended forms of preventive detention for the sake of public safety within the next 20-30 years, a proposal certainly calling for more critical scrutiny elsewhere (Rose, 2010).

\section{CONCLUSION AND OUTLOOK}

With respect to the question raised by Jan Slaby, the examples of cognitive enhancement and (im)moral neuroscience strongly suggest that notwithstanding the influences of neuro-collaborations and related funding schemes within academia, we scholars indeed collectively overestimate the practical and translational social impact of this research so far. The communicated promises as well as the scholarly and public attention given to these possibilities are, in my view, in no way justified by the scientific possibilities. It goes without saying that this tentative conclusion cannot readily be generalized to different examples or initiatives like the Human

\footnotetext{
${ }^{5}$ See also Nature News of October 302009 featuring a murder case in Italy (http://www.nature.com/news/2009/091030/full/news.2009.1050.html) or the Nature special "Science in Court" (http://www.nature.com/news/specials/ scienceincourt/index.html), both accessed on February 232014.
} 


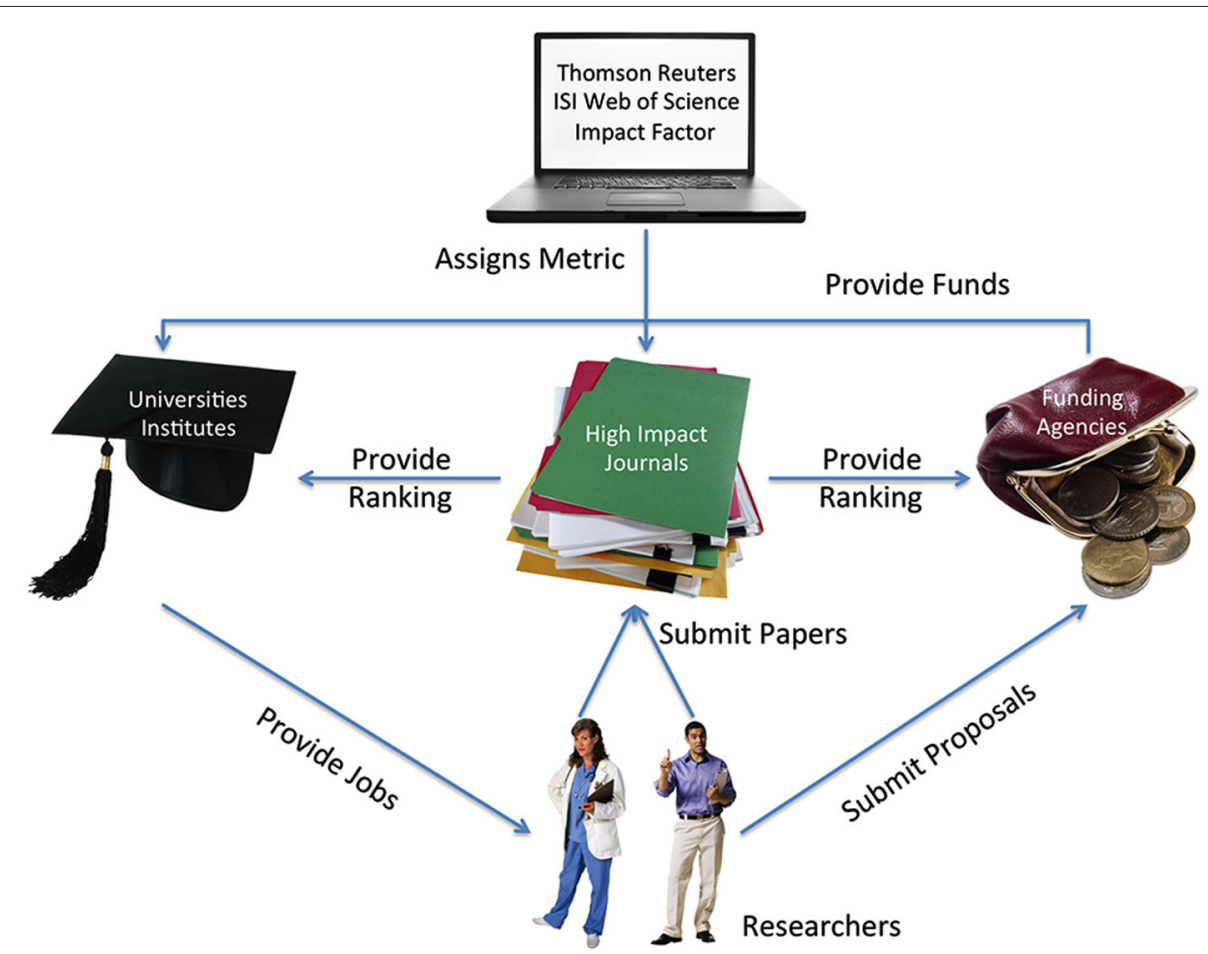

FIGURE 2 | The scientific incentive system, simplified. Researchers compete for scarce places in high-impact science journals and limited research funds. Their access to these resources is decisive for hiring and, eventually, tenure decisions at universities or research institutes. The ISI Impact Factor itself is an arbitrary measure calculated by a commercial company, now owned by Thomson Reuters, representing the average number of citations of a journal's articles in the previous 2 years, a measure originally developed for librarians. It is used by knowledge and funding institutions to assess scientists' quality, because it seems to meet the needs of a standardized, easily comparable, and objective way of assessing research and researchers. Many scholars believe that this incentive system negatively influences decisions of scientists, particularly young scholars competing for tenured positions. Figure created using Microsoft ${ }^{\circledR}$ Clip Art. Used with permission from Microsoft (http://www.microsoft.com/).
Brain Project or the BRAIN Initiative, although they are likely to be driven by the same incentive structures. This emphasizes the importance to raise considerable concerns with respect to neuroscience communication. In the remainder of this paper I will thus present two explanations of the found communication patterns and suggest improvements:

First, particularly with respect to the possibilities and limitations of functional Magnetic Resonance Imaging (fMRI) as a research tool we could witness exaggerated expectations regarding knowledge about the functioning of the human mind that were gradually diminished by a focus on biological, psychological, and statistical limitations (Logothetis, 2008; Vul et al., 2009; Margulies, 2011). Communication patterns in print media from 1995-2004 show clear evidence for an overwhelming optimism with respect to the technology's possibilities (Racine et al., 2005, 2010), while for the period from 2005-2009, including online media, the presence of critical reports was emphasized (Whiteley, 2012), reflecting a trend in scientific reviews (Rachul and Zarzeczny, 2012). Felix Hasler suggested that this exemplifies a Gartner Hype Cycle where a technology trigger leads to a peak of inflated expectations, followed by a trough of disillusionment, a slope of enlightenment, and, finally, a plateau of productivity (Hasler, 2012). However, the neurosciences as a whole are so diverse and complex that this explanatory pattern should presently only be applied to single technologies such as fMRI.

Second, the exaggerated promises could be instances of strategic behavior driven by scarce means in a competitive and uncertain environment. Analyses of science communication in general emphasized publication and commercialization pressures, media practices, and public expectations, as feeding a "hype pipeline" (Bubela et al., 2009; Caulfield and Condit, 2012). These pressures may counteract basic scientific values such as honesty, doubt/skepticism, or openness (IAC/IAP, 2012; DFG, 2013). Indeed, current or past presidents of neuroscience institutions worldwide emphasized the pressure to publish in selective highimpact journals and achieve competitive research grants (Amara et al., 2011) and warned against the "corrupting force" of superficial standardized measures of scientific quality like the Impact Factor (Marder et al., 2010).

The present situation of the scientific communication and academic incentive system (see Figure 2) actually exemplifies the behaviorists' social engineering technology: that the environment's reinforcement structure, the contingencies of punishment and reward, influences behavior (Skinner, 1971). Many scholars do what they perceive as a success-maximizing strategy in order to receive the rewards of public attention, research funds, the 
possibility to publish in high-impact journals, and tenured positions. Critical Neuroscience contributes to understand this reward system. However, it would be naïve to think that these forces are restricted to the neurosciences; or that scholars actively engaging in the sociology of neuroscience in general or Critical Neuroscience in particular are completely immune to the present pressures and rewards.

In a reflection on the "neuroscientific turn", Melissa Littlefield and Jenell Johnson discuss the possibility that we ourselves may construct some of the risks that we subsequently propose to manage and that not only neuroscientists, but also scholars from the humanities and social sciences are under pressure to adapt to an academic world with scarce resources, favoring scientific research promising practical significance (Littlefield and Johnson, 2012). Such pressures may also affect critical scholars selecting research questions or investigating institutions where interesting things are happening to increase communication success at the cost of representativity and neutrality. Neuroethics was originally conceived to protect society from abuses of neurotechnology, but due to occupational needs and dependencies it may also shield neuroscience from society's critique (Conrad and De Vries, 2011). It would be deplorable if Critical Neuroscience followed this example. It should be noted, though, that some of its members explicitly expressed awareness of such pressures and distanced themselves from neuroethics (Choudhury et al., 2009; Slaby and Choudhury, 2012).

A general Critical Science movement is necessary in order to change the incentive structure (Nosek et al., 2012), to guarantee scholarly autonomy and independence, and to promote behavior in accordance with basic scientific norms and values (IAC/IAP, 2012; DFG, 2013). That is, Critical Neuroscience is necessary; but it is not sufficient. We need to move past Sperry's initial proposal, to work according to principles that guarantee scholarly and public trust in the long run instead of promising applications as a successful fundraising strategy in the short run at the cost of credibility. We need a Critical Science structure that also rewards doubt, skepticism, authenticity, honesty, and reluctance to oversimplify science or prematurely translate scientific knowledge into practice even when this is uncomfortable. I followed a two-fold strategy to answer Slaby's question whether the neurosciences indeed have the wide-ranging effects often assumed; based on my limited analysis, both parts point in the same direction: the underlying issues go beyond the neurosciences and beyond Critical Neuroscience.

\section{ACKNOWLEDGMENTS}

I would like to thank Boris B. Quednow for fruitful discussions on the cognitive enhancement debate and the Barbara Wengeler Foundation for supporting my research visit to the University Clinics Zürich. I am also grateful for the two peer reviewer's helpful comments for improving an earlier version of this manuscript.

\section{REFERENCES}

Abraham, J. (2010). Pharmaceuticalization of society in context: theoretical, empirical and health dimensions. Sociology-the J. Br. Sociol. Assoc. 44, 603-622. doi: 10. 1177/0038038510369368

Amara, S. G., Grillner, S., Insel, T., Nutt, D., and Tsumoto, T.. (2011). Neuroscience in recession? Nat. Rev. Neurosci. 12, 297-302. doi: 10.5402/neuroscience
Becker, P. (2012). "The neurosciences and criminology: how new experts have moved into public policy and debate," in Engineering Society: The Role of the Human and Social Sciences in Modern Societies, 1880-1980, eds K. Brückweh, D. Schumann, R. F. Wetzell and B. Ziemann (Houndmills: Plagrave Macmillan), 119-139.

Beddington, J., Cooper, C. L., Field, J., Goswami, U., Huppert, F. A., Jenkins, R., et al. (2008). The mental wealth of nations. Nature 455, 1057-1060. doi: 10. $1038 / 4551057 \mathrm{a}$

Berker, S. (2009). The normative insignificance of neuroscience. Philos. Public Aff. 37, 293-329. doi: 10.1111/j.1088-4963.2009.01164.x

Bioethics Council (US President's Council on Bioethics) (2003). Beyond Therapy: Biotechnology and the Pursuit of Happiness. 1st Edn. New York: ReganBooks. xxi, 328.

Bubela, T., Nisbet, M. C., Borchelt, R., Brunger, F., Critchley, C., Einsiedel, E., et al. (2009). Science communication reconsidered. Nat. Biotechnol. 27, 514518. doi: 10.1038/nbt0609-514

Bush, G. H. W. (1990). Presidential Proclamation 6158: Project on the Decade of the Brain. Washington, DC: Library of Congress.

Caulfield, T., and Condit, C. (2012). Science and the sources of hype. Public Health Genomics 15, 209-217. doi: 10.1159/000336533

Choudhury, S., Nagel, S. K., and Slaby, J. (2009). Critical neuroscience: linking neuroscience and society through critical practice. Biosocieties 4, 61-77. doi: 10 . $1017 /$ s1745855209006437

Conrad, E. C., and De Vries, R. (2011). "Field of dreams: a social history of neuroethics," in Sociological Reflections on the Neurosciences, eds M. Pickersgill and I. Van Keulen (Bingley: Emerald), 299-324.

Currie, J., Stabile, M., and Jones, L. E. (2013). Do Stimulant Medications Improve Educational and Behavioral Outcomes for Children with ADHD? Cambridge, MA: National Bureau of Economic Research.

DFG (Deutsche Forschungsgemeinschaft; German Research Foundation) (2013). Proposals for Safeguarding Good Scientific Practice: Recommendations of the Commission on Professional Self Regulation in Science. Weinheim: Wiley-VCH.

Farah, M. J., Illes, J., Cook-Deegan, R., Gardner, H., Kandel, E., King, P., et al. (2004). Neurocognitive enhancement: what can we do and what should we do? Nat. Rev. Neurosci. 5, 421-425. doi: 10.1038/nrn1390

Foresight (Foresight Mental Capital and Wellbeing Project) (2008). Final Project Report. London: The Government Office for Science.

Gazzaniga, M. S. (2005). The Ethical Brain. New York: Dana Press. xix, 201.

Greely, H., Sahakian, B., Harris, J., Kessler, R. C., Gazzaniga, M., Campbell, P., et al. (2008). Towards responsible use of cognitive-enhancing drugs by the healthy. Nature 456, 702-705. doi: 10.1038/456702a

Greene, J. D., Sommerville, R. B., Nystrom, L. E., Darley, J. M., and Cohen, J. D. (2001). An fMRI investigation of emotional engagement in moral judgment. Science 293, 2105-2108. doi: 10.1126/science.1062872

Greene, J. D., Nystrom, L. E., Engell, A. D., Darley, J. M., and Cohen, J. D. (2004). The neural bases of cognitive conflict and control in moral judgment. Neuron 44, 389-400. doi: 10.1016/j.neuron.2004.09.027

Greene, J. D. (2008). "The secret joke of kant's soul," in Moral Psychology. The Neuroscience of Morality: Emotion, Brain Disorders and Development, ed W. Sinnott-Armstrong (Cambridge, MA: MIT Press), 35-79.

Hasler, F. (2012). Neuromythologie: eine Streitschrift gegen die Deutungsmacht der Hirnforschung. Bielefeld: Transcript.

Helmuth, L. (2001). Cognitive neuroscience - moral reasoning relies on emotion. Science 293, 1971-1972. doi: 10.1126/science.293.5537.1971a

Hughes, V. (2010). Science in court: head case. Nature 464, 340-342. doi: 10. $1038 / 464340 \mathrm{a}$

IAC/IAP (InterAcademy Council/IAP - the global network of science academies) (2012). Responsible Conduct in the Global Research Enterprise: A Policy Report. Amsterdam: InterAcademy Council.

Joyce, R. (2008). "What neuroscience can (and cannot) contribute to metaethics," in The Neuroscience of Morality: Emotion, Brain Disorders and Development, ed W. Sinnott-Armstrong (Cambridge, MA: MIT Press), 371-394.

Kahane, G. (2011). Evolutionary debunking arguments. Nous 45, 103-125. doi: 10. 1111/j.1468-0068.2010.00770.x

Littlefield, M. M., and Johnson, J. M. (2012). "Introduction: theorizing the neuroscientific turn-critical perspectives on a translational discipline," in The Neuroscientific Turn: Transdisciplinarity in the Age of the Brain, eds M. M. Littlefield and J. M. Johnson (Ann Arbor: The University of Michigan Press), $1-25$. 
Logothetis, N. K. (2008). What we can do and what we cannot do with fMRI. Nature 453, 869-878. doi: 10.1038/nature06976

Marder, E., Kettenmann, H., and Grillner, S. (2010). Impacting our young. Proc. Natl. Acad. Sci. U S A 107, 21233. doi: 10.1073/pnas.1016516107

Margulies, D. S. (2011). "The salmon of doubt: six months of methodological controversy within social neuroscience," in Critical Neuroscience: A Handbook of the Social and Cultural Contexts of Neuroscience, eds S. Choudhury and J. Slaby (Chichester: Wiley-Blackwell), 273-285.

Moll, J., Zahn, R., de Oliveira-Souza, R., Krueger, F., and Grafman, J. (2005). The neural basis of human moral cognition. Nat. Rev. Neurosci. 6, 799-809. doi: 10. 1038/nrn1768

Moore, G. E. (1903). Principia Ethica. Cambridge: Cambridge University Press. xxvii, 232.

Nadelhoffer, T., and Nahmias, E. A., and Nichols, S. (2010). Moral Psychology : Historical and Contemporary Readings. Malden, MA: Wiley-Blackwell.

Nosek, B. A., Spies, J. R., and Motyl, M. (2012). Scientific utopia: II. Restructuring incentives and practices to promote truth over publishability. Perspect. Psychol. Sci. 7, 615-631. doi: 10.1177/1745691612459058

Pandolfi, F. M. (1993). European decade of brain research. Ital. J. Neurol. Sci. 14, 395-397. doi: 10.1007/BF02340729

Partridge, B. J., Bell, S. K., Lucke, J. C., Yeates, S., and Hall, W. D. (2011). Smart drugs "as common as coffee": media hype about neuroenhancement. PLoS One 6:e28416. doi: 10.1371/journal.pone.0028416

Quednow, B. B. (2010). Ethics of neuroenhancement: a phantom debate. Biosocieties 5, 153-156. doi: 10.1057/biosoc.2010.13

Rachul, C., and Zarzeczny, A. (2012). The rise of neuroskepticism. Int. J. Law Psychiatry 35, 77-81. doi: 10.1016/j.ijlp.2011.12.008

Racine, E., Waldman, S., Rosenberg, J., and Illes, J. (2010). Contemporary neuroscience in the media. Soc. Sci. Med. 71, 725-733. doi: 10.1016/j.socscimed.2010. 05.017

Racine, E., Bar-Ilan, O., and Illes, J. (2005). fMRI in the public eye. Nat. Rev. Neurosci. 6, 159-164. doi: 10.1038/nrn1609

Raine, A. (2013). The Anatomy of Violence: The Biological Roots of Crime. New York:Pantheon Books.

Rasmussen, N. (2008a). America's first amphetamine epidemic 1929-1971: a quantitative and qualitative retrospective with implications for the present. Am. J. Public Health 98, 974-985. doi: 10.2105/AJPH.2007.110593

Rasmussen, N. (2008b). On speed: the many lives of amphetamine. New York; London: New York University Press. ix, 352, [38] of plates.

Repantis, D., Schlattmann, P., Laisney, O., and Heuser, I. (2010). Modafinil and methylphenidate for neuroenhancement in healthy individuals: a systematic review. Pharmacol. Res. 62, 187-206. doi: 10.1016/j.phrs.2010.04.002

Rose, N. (2010). 'Screen and intervene': governing risky brains. Hist. Human Sci. 23, 79-105. doi: 10.1177/0952695109352415

Rubin, L. C. (2004). Merchandising madness: pills, promises and better living through chemistry. J. Pop. Cult. 38, 369-383. doi: 10.1111/j.0022-3840.2004. 00117.x

Satel, S., and Lilienfeld, S. O. (2013). Brainwashed: The Seductive Appeal of Mindless Neuroscience. New York, NY: Basic Books.

Sawhill, J. C. (1979). Role of science in higher-education. Science 206, 281-281.

Schleim, S. (2008). Moral physiology, its limitations and philosophical implications. Jahrbuch für Wissenschaft und Ethik 13, 51-80.

Schleim, S., and Schirmann, F. (2011). Philosophical implications and multidisciplinary challenges of moral physiology. Trames-J. Humanit. Soc. Sci. 15, 127146. doi: 10.3176/tr.2011.2.02
Schleim, S. (2010). Second thoughts on the prevalence of enhancement response. Biosocieties 5, 484-485. doi: 10.1057/biosoc.2010.32

Schleim, S. (2005). The ethical brain. J. Conscious. Stud. 12, 87-90.

Schleim, S. (forthcoming). "The half-life of the moral dilemma task: a case study in experimental (neuro-) philosophy," in Handbook of Neuroethics, eds J. Clausen and N. Levy (Berlin: Springer).

Sharpe, K. (2014). Medication: the smart-pill oversell. Nature 506, 146-148. doi: 10. $1038 / 506146 \mathrm{a}$

Singer, P. (2005). Ethics and intuitions. J. Ethics 9, 331-352. doi: 10.1007/s10892005-3508-y

Skinner, B. F. (1971). Beyond Freedom and Dignity. Toronto: Bantam. 225.

Slaby, J., and Choudhury, S. (2012). "Proposal for a critical neuroscience," in Critical Neuroscience: A Handbook of the Social and Cultural Contexts of Neuroscience, eds S. Choudhury and J. Slaby (Malden, MA: Wiley-Blackwell), 29-51.

Slaby, J. (2010). Steps towards a critical neuroscience. Phenomenology Cogn. Sci. 9, 397-416. doi: 10.1007/s11097-010-9170-2

Smith, M. E., and Farah, M. J. (2011). Are prescription stimulants "smart pills"? The epidemiology and cognitive neuroscience of prescription stimulant use by normal healthy individuals. Psychol. Bull. 137, 717-741. doi: 10.1037/a00 23825

Sperry, R. W. (1981). Changing Priorities. Annu. Rev. Neurosci. 4, 1-15. doi: 10. 1146/annurev.ne.04.030181.000245

van Gerven, J., and Cohen, A. (2011). Vanishing clinical psychopharmacology. Br. J. Clin. Pharmacol. 72, 1-5. doi: 10.1111/j.1365-2125.2011.04021.x

Vrecko, S. (2013). Just how cognitive is "Cognitive Enhancement"? On the significance of emotions in university students' experiences with study drugs. $A J O B$ Neurosci. 4, 4-12. doi: 10.1080/21507740.2012.740141

Vul, E., Harris, C., Winkielman, P., and Pashler, H.. (2009). Puzzlingly high correlations in fMRI studies of emotion, personality and social cognition. Perspect. Psychol. Sci. 4, 274-290. doi: 10.1111/j.1745-6924.2009.01126.x

Waldmann, M. R., Nagel, J., and Wiegmann, A. (2012). "Moral judgment," in The Oxford Handbook of Thinking and Reasoning, eds K. J. Holyoak and R. G. Morrison (Oxford: Oxford University Press), 364-389.

Whiteley, L. (2012). Resisting the revelatory scanner? Critical engagements with fMRI in popular media. Biosocieties 7, 245-272. doi: 10.1057/biosoc.2012.21

Williams, S. J., Seale, C., Boden, S., Lowe, P., and Steinberg, D. L. (2008). Waking up to sleepiness: modafinil, the media and the pharmaceuticalisation of everyday/night life. Sociol Health Illn. 30, 839-855. doi: 10.1111/j.1467-9566.2008. 01084.x

Conflict of Interest Statement: The author declares that the research was conducted in the absence of any commercial or financial relationships that could be construed as a potential conflict of interest.

Received: 25 February 2014; accepted: 03 May 2014; published online: 20 May 2014. Citation: Schleim S (2014) Critical neuroscience-or critical science? A perspective on the perceived normative significance of neuroscience. Front. Hum. Neurosci. 8:336. doi: 10.3389/fnhum.2014.00336

This article was submitted to the journal Frontiers in Human Neuroscience.

Copyright $(\odot) 2014$ Schleim. This is an open-access article distributed under the terms of the Creative Commons Attribution License (CC BY). The use, distribution or reproduction in other forums is permitted, provided the original author(s) or licensor are credited and that the original publication in this journal is cited, in accordance with accepted academic practice. No use, distribution or reproduction is permitted which does not comply with these terms. 